\title{
Social Work in Natural Disasters: The Case of Spirituality and Post-traumatic Growth
}

\author{
Li-ju Jang \\ Walter F. LaMendola
}

\begin{abstract}
This study explored the role of social work in natural disasters by examining the relationship between spi rituality and the posttraumatic growth of people in a collectivist culture. In this case, a retrospectivestudy was conducted among people in Taiwan who had survived a major earthquake five years earlier. The hypothesis tested was that those who reported higher levels of spirituality would also report higher levels of posttraumatic growth. A concurrent triangulation mixed-methods design wasemployed for thisstudy. Six hundred and forty participantscompleted the Posttraumatic Growth Inventory (PTGI). Twenty-eight others participated in semistructured in-depth interviews. Results indicatethat, in Taiwan-described hereasa collectivist culture - traditional cultural narratives around suffering and adversity, many of which are voiced as spiritual beliefs, have a significant effect on posttraumatic growth. In this situation, social workers need to work with or support spiritual leaders, folk healers, and indigenous religious organizations, as they providehelping services. Respect for cultural differencesmay requirethat social workers primarilyact ascommunityorganizersor developers, not diniciansfocusing on coordination and development of material resources.
\end{abstract}

Keywords: Spirituality, posttraumatic growth, natural disaster, Hakka spi rit, symbolicinteractionism

\section{INTRODUCTION}

On September 21, 1999, a devastating earthquake with a magnitude of 7.6 on the Richter scale, which Taiwanese people refer to as the 921 Earthquake, struck central Taiwan. The earthquake was responsible for approximately 2,423 deaths and 11,305 injuries. More than 100,000 people were left homeless. Of all the affected townships, Tung Shih suffered the highest death toll, with 358 ("Social aid," n.d.; Liao, 1999). This article reports on a study of Tung Shih earthquake survivors and service providers, with a focus on social workers and the extent to which spirituality contributed to the posttraumatic growth of survivors.

Li-ju Jang, Ph.D. is an assistant professor in the School of Medical Sociology and Social Work, Chung Shan Medical University, Taiwan, Republic of China. Walter F. LaMendola, Ph.D. is professor, Graduate School of Social Work, University of Denver, Denver, CO 80208.

Copyright $^{\odot} 2007$ Advances in Social Work Vol. 8 No. 2 (Fall 2007) 305-316.

Indiana University School of Social Work. 


\section{SPIRITUALITY AND NATURAL DISASTERS}

Tedeschi and Calhoun (1995) have argued that spirituality-in the form of religious beliefs-can offer a direct means for survivors to perceive benefit evolving from disasters. Later work has continued to make the case, though in more general terms. For example, Saleebey (2002) claimed that spirituality influences survivor coping styles both in the face of disaster and in their ensuing daily life. Cadell, Regehr, and Hemsworth (2003) agreed, arguing further that making sense of an event-attaching meaning to it-is an essential component of successful coping that survivors often attempt to resolve through spirituality (p. 280). Nathanson (2003) contributed an important and perhaps distinguishing qualifier by, not only claiming that "spirituality is an important force in recovery" (p. 63), but also by pointing out that spirituality has historically been associated, across different cultures and religions, with the human search to find meaning in suffering. This was also noted by Tedeschi and Calhoun (1995, 1996), who incorporated spirituality as a subscale in their Posttraumatic Growth Inventory (PTGI).

In Taiwan, a collectivist culture with strong clan ties, spirituality is seen as both a philosophy and a way of life-primarily expressed through a variety of religious traditions. Notions of living harmoniously with Nature are a predominant feature of spirituality. Nature is an active force in everyday life, particularly in the region included in this study, where natural disasters, though varying in intensity and severity, are frequent. Generally speaking, people in Taiwan consider natural disasters the will of the gods (Davison \& Reed, 1998; Jordan, 1999). Spirituality in Taiwan is based on a set of beliefs in the fundamental interconnectedness of all natural things and all forms of life, that "all things of heaven and earth are connected by the life force" (Davison \& Reed, 1998, p. 32).

These cultural beliefs conform to a pattern strongly noted by social work writers in Western cultures and subcultures, where investigations also indicate that a conflation of spirituality and religion occur in social performance (Amato-von Hemert, 1994; Canda, 1998; Coholic, 2003; Lowenberg, 1988; Sheridan, Bullis, Adcock, Berlin, \& Miller, 1992). For example, in Coholic's study of spirituality and religion among feminists, Coholic noted that, while spirituality and religion are conceptualized in different ways, they "overlap and influence each other..." (p. 49). Further, the reports of her study participants emphasized:

The development of spirituality is, above all, a complex and lifelong process that sometimes encompasses struggle. The process of spiritual development can be influenced by family, friends, culture, religious/spiritual traditions, and transformative life events, which can act as catalysts for spiritual discovery and exploration (p. 62).

Every one of the influences on the process of spiritual development described by Coholic (2003) are important to social workers and are applicable to the situation described in this study. However, the study situation is also notable as an example of the difficulties of conducting Western World social work successfully 
in a collectivist culture like Taiwan. The cultural narrative of the Hakka spirit in Taiwan, described briefly in the next section and elsewhere (Jang \& LaMendola, 2006), is an example. In the spirit of the Hakka pioneers, the narrative of their past becomes what Mink (1987) would call a “...primary cognitive instrument ... rivaled only by theory and metaphor as irreducible ways of making the flux of experience comprehensible" (p. 3). Survivors of the earthquake especially note the palpable influence of Hakka aphorisms on their behavior. This type of narrative contributes as well to the development of what Hieb (2002), in his study of the Hopi, has called a "moral community." Such beliefs are considered a key facet to consider in contemporary risk management (Paton, 2006) and social work interventions; for example, it is thought that beliefs that a spiritual life force is "watching over" daily needs may bring great comfort to survivors and actually promote resilience and growth in the aftermath of trauma.

Growth from trauma is a notion that can escape notice in much of the social work disaster literature. While definitions of resilience, common in social work (e.g., Barker, 1999, p. 411), infer that there are intrinsic resources that can be called upon to maintain or regain pre-disaster levels of functioning, recent research has gone further, identifying transformations that go beyond a return to pre-disaster functioning levels in a manner characterized by growth (Paton, Violanti \& Smith, 2003; Violanti, Paton, \& Dunning, 2000).

Violanti et al. (2000) have acknowledged that the paradigm in disaster studies is progressively shifting from a pathologic one with a focus on loss or negative psychological outcomes to a salutogenic one. Violanti et al. claimed that a salutogenic paradigm directs researchers to look at natural coping resources and encourages them to consider how individuals, families, and communities can draw upon family and social support, as well as other resources to facilitate resilience. Salutogenesis refers to people's ability to thrive in disasters, to achieve greater personal strength, and to have a better understanding of the disaster. In line with Violanti et al., Norwood, Ursano, and Fullerton (2000) have suggested that a paradigm shift from a focus on disease to health is necessary in the field of disaster psychiatry. They have encouraged psychiatrists to facilitate the natural recovery process and prevent psychiatric concerns, instead of treating pathology.

In addition, Ursano, Fullerton, and Norwood (1995) found that, for some survivors, trauma and loss facilitate a move toward health. They argued that a traumatic experience can help survivors recognize a previously disorganized life and re-evaluate their values and goals-citing other disaster studies to support their claims:

Many survivors of the 1974 tornado in Xenia, Ohio . . . learned that they could handle crises effectively (84\%) and believed that they were better off for having met this type of challenge (69\%) (Taylor, 1997; Quarentelli, 1985) ... Sledge and colleagues (1980) found that approximately one-third of U.S. Air Force Vietnam-era prisoners of war reported having benefited from their prisoner of war experience; they believed that they had developed an important reprioritization of their life goals, placing new emphasis on the importance of family and country (p. 197). 


\begin{tabular}{|l|}
\hline Table 1: Hakka Spirit \\
\hline $\begin{array}{l}\text { Migrated from China to Taiwan without a penny } \\
\text { Worked hard tilling the fields and mountains } \\
\text { Lived frugally for decades without complaint } \\
\text { The tradition of frugality and diligence passed on from generation to generation } \\
\text { without change in three hundred years } \\
\text { Never, never, never abandon the Hakka spirit } \\
\text { Living standards are improving, society is change } \\
\text { Traditional morals and values are facing challenges } \\
\text { Advice to all the Hakka is to seek perfection in conscience } \\
\text { Be a righteous and kindhearted person just like our ancestors } \\
\text { Never, never, never forget the teaching of our ancestors }\end{array}$ \\
\end{tabular}

Symbolic interactionists might argue that spirituality would be, to some extent, shaped by the traumatic experience and constructed continuously through interactions between people, creating bonds of shared meanings in the process. In such a view, the social work frame of reference for spirituality would include: a) social processes, b) social norms, c) shared meanings, and d) context (Blumer, 1969; Mead, 1934). This is the frame of reference for spirituality in this study-as a dynamic but also a historically-based narrative that "everybody knows" in Mink's $(1987,2001)$ terms - onethat re-minds people as they act and react to their situation. An example of this is a Hakka folk song (Table 1) known by most people in the region.

For the authors, this song represents the Hakka view of the world, a world occupied by a people who are guided by the practices of those before them, but who ultimately use the memories of the past to create new forms in the present. It allowed us, as social work researchers, to hear the human promise of disaster. In that promise, survivors act in purposeful ways, reminded by their ancestors and their historical understanding to use social practices of great power, such as those embedded in their song, as a spiritual narrative to transform their lives.

\section{METHODOLOGY}

A mixed-methods design that Creswell (2003) terms a concurrent triangulation approach was employed. For the quantitative portion of the study, it was assumed that a person who reports posttraumatic growth (PTG) must have a level of resilience sufficient enough to support growth. The focus was on measuring posttraumatic growth. The Chinese version of Posttraumatic Growth Inventory (PTGI) was used to test a general hypothesis that those "participants who report contin- 
uous religious affiliation will have a significantly higher score on the PTGI than those who report no religious affiliation." Spirituality was measured by participant reports of continu ous religi ous affiliation-an indicator based on whether or not participants reported religious affiliation before and after the 921 Earthquake. While such an indicator would be understandably suspect in Western studies, the public admission of continuous religious affiliation in Taiwan is a serious matter and represents a deep spiritual commitment.

In the qualitative portion of the study, study participants, including survivors, service providers, and volunteers, were given opportunities to speak in their own language to share their stories related to changes experienced as a result of the 921 Earthquake and the contribution of spirituality. Thestories were taken as narratives about posttraumatic growth.

\section{Instrumentation}

The Posttraumatic Growth Inventory developed by Tedeschi and Calhoun (1995, 1996) was employed to assess posttraumatic growth of the 921 Earthquake survivors in Tung Shih. They first reviewed studies of perceived benefits and generated 34 items, then performed a principal component analysis (PCA) on those 34 items using varimax rotation, which assumed zero correlation between factors. They reported that five factors were extracted, which accounted for $55 \%$ of the common variance. A total of 21 items, with loading greater than .5 and cross-loading on any other factor no greater than .4, were included in the final version of the Posttraumatic Growth Inventory. Then, Tedeschi and Calhoun performed a Pearson product-moment correlation between the total scores based on the 34item and 21-item versions of the PTGI. The results indicated that there was an almost perfect correlation ( $r=98$ ) between these two versions of PTGI.

Further, Tedeschi and Calhoun $(1995,1996)$ reported that the internal consistency of the 21-item version of PTGI was $\alpha=90$, and for the five factors, $\alpha$ ranged from .67 to .85 . They claimed that all items were measuring a similar underlying construct, but nonewas overly redundant with the others, based on the findings of corrected item-scale correlations ( $r=35$ to $r=63)$. Its test-retest reliability over a twomonth period was $r=71$.

Because the written language used by the target population was Chinese, a Chinese version of the PTGI was required. Hence, the 21 -item version of the PTGI was translated into Chinese. The first Chinese version of the PTGI was presented to a professional interpreter and four service providers who worked with survivors of the 921 Earthquake to ensure accuracy and appropriateness of the language use and word choice. Required revisions were made based on those experts' comments. The final Chinese version of the PTGI was a 21 -item self-rating scale with a 6-point response format $(0=1$ did not experience this change as a result of the 921 Earthquake, $5=1$ experienced this change to a very great degree as a result of the 921 Earthquake). Higher scores indicated higher levels of posttraumatic growth. A total PTGI score of zero might suggest no posttraumatic growth occurred. Any score greater than zero indicated some levels of posttraumatic growth. Cronbach's alpha estimate for the Chinese version of PTGI in the present study was $\alpha=96$. Internal consistency reliabilities for five subscales were presented in Table 2. 


\begin{tabular}{|cc|}
\hline Table 2: & $\begin{array}{c}\text { Cronbach's Al pha Estimates for the ChineseVersion of Posttraumatic Growth } \\
\text { Inventory FiveSubscales }\end{array}$ \\
\hline PTGI Subscales & Cronbach's Alpha \\
Relating to Others & .89 \\
New Possibilities & .84 \\
Personal Strength & .86 \\
Spiritual Change & .85 \\
Appreciation of Life & .77 \\
\hline
\end{tabular}

\section{SAMPLING}

A single-stage cluster sampling strategy was used in the recruitment of survey participants. The population of Tung Shih was broken down into clusters (Singleton \& Straits, 1999) consisting of four natural groupings: a) schools, b) religious groups, c) governmental agencies, and d) community members. A total of 17 key informants from schools, religious groups, governmental agencies, and community assisted with questionnaire distribution and collection. Recruits for interviews were identified using a snowball sampling strategy. The criteria were that prospective participants must be: a) 18 years or older and survivors of the 921 Earthquake or b) service providers to survivors in Tung Shih, or c) volunteers who were involved in relief efforts and/or reconstruction projects in Tung Shih.

\section{Data Collection and Analysis}

To ensure a reasonable survey response rate, the PTGI was delivered in person by key informants or researchers. "Face" is very important to the people of Tai wan. It was thought that people were more likely to respond to this study if they were concerned about saving the "face" of themselves and the person who delivered the surveys. A total of 1,250 surveys were distributed to potential participants, resulting in a total of 640 completed surveys. Twenty-eight in-depth interviews were conducted. A parallel mixed analysis approach was employed, meaning that the results from the quantitative and qualitative analysis were not compared or consolidated until both sets of data analyses were completed (Onwuegbuzie \& Teddlie, 2003).

\section{Participants}

A slight majority of survey participants were female (65\%) and Hakka (57\%). Many were high school graduates (33\%). Both before and after the disaster, about three quarters of the survey participants reported affiliating with Buddhism, Taoism, or Folk Religion. The 28 individuals who were interviewed included 16 survivors, six service providers, and six volunteers. Fourteen interviewees were in their 40 s at the time of interview. Twenty-five reported experiencing loss of loved ones or were suffering from property damage. Fifteen participants reported affiliations with folk religion. 


\section{RESULTS}

\section{Quantitative Findings}

Of the participants age 46 years or older, $88 \%$ reported "continuous religious affiliation," whereas $68 \%$ of the participants ranging in age between 26 and 35 years reported "continuous religious affiliation." Ninety-seven percent of the participants in the "less than junior high" education group reported "continuous religious affiliation," while $65 \%$ of the participants in the "college or higher" education group reported "continuous religious affiliation." In general then, continuous religious affiliation was highest among study participants who were middle-aged or older and had not completed junior high.

About $45 \%$ of the participants in the "continuous religious affiliation" group, but only $23 \%$ of the participants in the "no religious affiliation" group, scored within the fourth or fifth quintile on the PTGI. To assess correlations among sample characteristics and the PTGI, the Pearson product-moment correlation was calculated (see Table 3).

\begin{tabular}{|lcccc|}
\hline \multicolumn{4}{|c|}{ Table 3: Intercorrelations Between Post-traumatic } & Growth and SampleCharacteristics \\
\hline \multicolumn{7}{l}{ 1. Age } & $\mathbf{1}$ & $\mathbf{2}$ & $\mathbf{3}$ & $\mathbf{4}$ \\
\hline 2. Education & - & $-.29^{* *}$ & $.23^{* *}$ & $.20^{* *}$ \\
3. Religious Affiliation & & - & $-.27^{* *}$ & .01 \\
4. Posttraumatic Growth Inventory & & & - & $.19^{* *}$ \\
Mean & 3.02 & 3.52 & 0.79 & - \\
SD & 1.10 & 1.21 & 0.41 & 22.66 \\
\hline Note $* * p<01$. & & & \\
\hline
\end{tabular}

Here, ageand education were treated as scale variables, because they had five or more ordered levels (Leech, Barrett, \& Morgan, 2005). The results showed that the PTGI was positively associated with age $(r=20, p<01)$ and religious affiliation $(r=19, p<01)$, which suggested that participants in the older age groups or those who reported continuous religious affiliation were more likely to score higher on the PTGI than others.

The result of an independent-sample t-test indicated that participants who reported continuous religious affiliation scored significantly higher on the PTGI than those who reported no religious affiliation, $\mathrm{t}(496)=4.63, \mathrm{p}<01$. The hypothesis that, those participants who report continuous religious affiliation will have a significantly higher score on the PTGI than those who report no religious affiliation, was supported by this finding. Further, a hierarchical regression model suggested that spirituality $(ß=19, p<01$ ) was a significant predictor of survivors' PTG. 


\section{Qualitative Findings}

Themes

Among the major themes important to social work that emerged from the interviews with survivors and service providers were three, which were based in traditional Taiwanese culture; namely, the role of fate and destiny, ancestor worship, and lessons from gods. The examples of each theme that follow are primarily extracts from interviews. In each case, social work notice is taken that survivors felt supported in their recovery and posttraumatic growth, regardless of the dominant theme that they expressed.

Traditional theme: Fate and destiny. Mr. Lu (participant names have been replaced with common Chinese family names) was a popular architectural designer who incorporated the concepts of Feng Shui and date-picking art into his designs. He commented that, “. . . with the knowledge of Feng Shui and datepicking art, I am able to provide extra services for my customers. My customers can expect 3-in-1 services from me!" Lu was an optimistic person, despite the calamities he experienced. He not only lost his wife and daughter to the disaster, but he was also paralyzed from the waist down dueto severe spine injury. Lu stated that he knew that the Feng Shui of hisfamily house was not good for his immediate family. He said that he had tried to change it, but he failed, because it involved all his extended family. Regarding his injury, Lu felt that people had done their best to help him. He stated that, if he could not be healed, it was because it was his destiny. "I believe in fate and I accept fate," Lu affirmed.

Generally, service providers reported that people in Tung Shih accepted natural disasters as the will of the gods. Ms. Jan, Mr. Hou, and Mr. Su reported that, when people in other areas experienced natural disasters, people in Tung Shih often said, "It's their turn now." To the people of Tung Shih, it was fair, because people took turns experiencing natural disasters.

Traditional theme: Ancestor worship. Ancestors-the experiences they survived, the resilience under great duress, and the values that they held-guide everyday behavior. Ms. Yu said:

Ancestor worship is a way to show our gratitude for the foundation they laid for us ... We are connected with our ancestors through daily ancestor worship and the annual tomb-sweeping festival. Those rituals constantly remind us not to bring shame to the family nameand not to forget our family duties.

Ms. Yu stressed that daily ancestor worship provided the necessary strength to move forward with her life, while reminding her about who she was and her duties to her people. She said that she felt assurance that her ancestors and gods were with her. Other survivors asked Taoist priests to check on the Feng Shui of their ancestral tombs, because they were afraid that their sufferings resulted from damaged ancestral tombs.

Traditional theme: Lessons from gods. Some survivors believed that people would continue experiencing natural disasters until they learned the lessons that the gods wanted them to learn. Ms. Liu cited a Buddhist master saying, "People 
experienced natural disaster because they did not live harmoniously with Nature. People were not honest with their fellowmen. Political turmoil and contentions among people resulted in natural disasters. Natural disaster was gods' way of cleansing evil doers." Ms. Jan stressed that, growing up in Taiwan, people were constantly being reminded about the folk saying, "Lift up your head and then you will know there are gods." People were told that gods watched people's deeds and thoughts. Gods rewarded people's good deeds and punished their evil doings.

\section{Helping Services}

Mr. Shu and Ms. Fu reported that several major hospitals set up medical booths, offering counseling services to survivors in Tung Shih, but that few survivors visited those "mental health professional" booths. Mr. Shu and Ms. Fu stated that the reason for the lack of use of the mental health professionals was that healing and recovery was associated with spirituality, not mental health. They reported that there were always long lines in front of booths offering religious remedies or folk healing arts. Mr. Shu and Ms. Fu commented that religious rituals were more powerful than professional counseling. They went on to emphasize that it was natural that survivors would prefer visiting a medium believed to be able to communicate with spiritual beings than a mental health professional. Mr. Shu also indicated that he participated in the seeding support group that was facilitated by a group of clinical psychologists from National Taiwan University. He said that he thought that the facilitators were good people, but somehow he felt that they could not bring inner peace to his life. Mr. Shu went on to explain that his spiritual beliefs provided explanations for many things that the psychologists could not explain. For example, there were proper spiritual rituals for the deceased to ensure that they were at peace that brought great comfort to survivors. Mr. Shu stressed that such beliefs were not superstitions but a matter of fact. He also pointed out that many survivors hired Feng Shui masters to rearrange their house settings, hoping the new arrangements could bring fortune to their families.

\section{DISCUSSION}

Study results indicate that, in Taiwan, a collectivist culture with widely shared cultural narratives spirituality has a significant effect on posttraumatic growth (PTG). This finding builds on Western studies that find that spirituality contributes to people's resilience and PTG (Cadell et al., 2003; Tedeschi \& Calhoun, 1995, 1996). In addition, a hierarchical regression model used in the analysis suggests that spirituality is a significant predictor of posttraumatic growth.

As may be commonly experienced in this type of study, there are unexplored levels of analyses and uneven use of data collection techniques. Due to the nature of Taiwan's conservative collectivist culture, a non-probability sampling strategy was utilized for the quantitative research and snowball sampling for the qualitative research. Taiwanese people are relational, and connections are very important to them, so that research techniques were employed that could ensure adequate response rates. It is also important to note that, because Tung Shih is located in a water source reserve area and no manufacturing plants are allowed to be built there, younger generations were more likely to study or work in other areas and were therefore not represented well in this study. In addition, the older gen- 
eration was more likely to be illiterate or elementary school dropouts and probably chose not to participate for those reasons. As a result, the majority of participants, in both the quantitative and qualitative studies, were more likely to be in their 30s to 50s at the time of the study. Finally, the PTGI used for the quantitative research was developed in an individualist culture in which the development of relationships following adverse experience may represent a unique change to social dynamics. In contrast, in collectivist societies, the importance and quality of social relationships is far higher under normal circumstances. Hence, our assumption, that the nature and implications of spiritual beliefs are sufficiently similar across cultures to allow the original PTGI scale to be used, may be questioned.

The difficulty of cross-cultural comparisons is not ignored by symbolic interactionists who would point out that meanings also vary between local cultures and contexts, and that they change over time. Despite these limits, it is arguable that the theory can provide social workers a rationale that supports understanding the manner in which the 921 disaster survivors in this study define the reality and meaning of the disaster. Further, symbolic interactionists view the self as dynamic, creative, and adaptive, a view that is congruent with the definition of resilience. This study contributes interesting possibilities to be further explored between such theoretical perspectives and their possible utility in the investigation of disasters in varying cultures (e.g., individualist vs. collectivist cultures).

The social work implications are much more involved than one might imagine from first glance. While it would seem to be relatively straightforward to support the emphasis on cultural appropriateness current in the field of social work today, in fact, the meaning of that in this context would be to advise social workers to work with and support spiritual leaders or folk healers who appear to be more acceptable and helpful to the survivors. Social workers would also need primarily to be community organizers, not clinicians focusing on coordination and development of material resources. In fact, possibly the most serious problem noted by participants was the lack of "government response" and the delay of providers in delivering material resources and aid-a situation echoed in the 2004 tsunami and, more recently, hurricane Katrina in the United States. Those delays, in themselves, cause traumatic effects. In other words, social workers need to consider the dominant cultural narratives as an asset and shape their roles accordingly-in terms of their contribution to recovery and growth. In this case, it seems likely that preventative work in the form of material preparation and response scenarios, the coordination and provision of immediate material aid, meeting health needs, and dealing with resource issues are of paramount importance.

\section{References.}

Amato-von Hemert, K. (1994). Should social work education address religious issues? Yes! Journal of Social Work Education, 30, 7-11.

Barker, R.L. (1999). The social work dictionary (4 $4^{\text {th }}$ ed.). Washington, D.C.: NASW Press. 
Blumer, H. (1969). Symbolic interactionism: Perspectiveand method. Englewood Cliffs, NJ: Prentice-Hall.

Cadell, S., Regehr, C., \& Hemsworth, D. (2003). Factors contributing to posttraumatic growth: A proposed structural equation model. American Journal of Orthopsychiatry, 73(3), 279-287.

Canda, E.R. (1998). Afterword. Linking spirituality and social work: Five themes for innovation. Social Thought, 18(2), 97-106.

Coholic, D. (2003, Spring). Incorporating spirituality in feminist social work perspectives. AFFILIA, 18(1), 49-67.

Creswell, J.W. (2003). Research design: Qualitative, quantitative, and mixed methods approaches ( $2^{\text {nd }}$ ed.). Thousand Oaks, CA: Sage.

Davison, G.M., \& Reed, B.E. (1998). Cultureand customs of Taiwan. Westport, CT: Greenwood Publishing Group.

Hieb, L.A. (2002). Social memory and cultural narrative: The Hopi construction of a moral community. Journal of theSouthwest, 44(1): 79-94.

Jang, L.J. \& LaMendola, W. (2006). The Hakka spirit as a predictor of resilience. In: D. Paton \& D. Johnston. Disaster resilience: An integrated approach. Springfield, IL: Charles C. Thomas.

Jordan, D.K. (1999). Gods, ghosts, \& ancestors: Folk religion in a Taiwanese village ( $3^{\text {rd }}$ ed.). San Diego, CA: Department of Anthropology, UCSD.

Leech, N.L., Barrett, K.C., \& Morgan, G.A. (2005). SPSS for intermediate statistics: Use and interpretation ( $2^{\text {nd }}$ ed.). Mahwah, NJ: Lawrence Erlbaum Associates.

Liao, Y.L. (Ed.). (1999). Trauma of century. Feng Yuan, Taiwan: Taichung County Government.

Lowenberg, F. (1988). Religion and social work practice in contemporary American society. NY: Columbia University Press.

Mead, G.H. (1934). Mind, self \& society: From the standpoint of a social behaviorist. Chicago, IL: The University of Chicago Press.

Mink, L.O. (1987). Historical understanding. Ithaca, NY: Cornell University Press.

Mink, L.O. (2001) Narrative form as a cognitive instrument. In G. Roberts (Ed.), Thehistory and narrative reader (pp. 211-220). New York: Routledge.

Nathanson, I. (2003). Spirituality and the life cycle. In T. Tirrito \& T. Cascio (Eds.), Religious organizations in community services: A social work perspective (pp. 63-77). New York: Springer.

Norwood, A.E., Ursano, R.J., \& Fullerton, C.S. (2000). Disaster psychiatry: Principles and practice. Psychiatric Quarterly, 71(3), 207-226.

Onwuegbuzie, A.J., \&Teddlie, C. (2003). A framework for analyzing data in mixed methods research. In A. Tashakkori \& C. Teddlie (Eds.), Handbook of mixed methods: In social \& behavioral research (pp. 351384). Thousand Oaks, CA: Sage.

Paton, D. (2006). Posttraumatic growth in disaster and emergency work. In L.G. Calhoun \& R.G. Tedeschi (Eds.), Handbook of posttraumatic growth: Research and practice. Mahwah, NJ: Lawrence Erlbaum Association.

Paton, D., Violanti, J.M., \& Smith, L.M. (Eds.). (2003). Promoting capabilities to manage posttraumatic stress: Perspectives on resilience. Springfield, IL: Charles C Thomas Publisher, Ltd.

Saleebey, D. (Ed.). (2002). The strengths perspective in social work practice ( $3^{\text {rd }}$ ed.). Boston, MA: Allyn \& Bacon.

Sheridan, M., Bullis, R., Adcock, C., Berlin, S., \& Miller, P. (1992). Serving diverse religious client populations: Issues for social work education and practice. Journal of Social Work Education, 28, 190-203.

Singleton, R.A., \& Straits, B.C. (1999). Approaches to social research. New York: Oxford University Press.

Tedeschi, R.G., \& Calhoun, L.G. (1995). Trauma and transformation: Growing in the aftermath of suffering. Thousand Oaks, CA: Sage.

Tedeschi, R.G., \& Calhoun, L.G. (1996). The post-traumatic growth inventory: Measuring the positive legacy of trauma. Journal of Traumatic Stress, 9(3), 455-471. 
The social aid to and placement of refugees in 921 big quake analysis. (n.d.). Taipei, Taiwan: [Department of Statistics, Ministry of Interior, Taiwan].

Ursano, R.J., Fullerton, C.S., \& Norwood, A.E. (1995, November/December). Psychiatric dimensions of disaster: Patient care, community consultation, and preventive medicine. Harvard Review of Psychiatry, 3(4), 196-209.

Violanti, J.M., Paton, D., \& Dunning, C. (2000). Posttraumatic stress intervention: Challenges, issues, and perspectives. Springfield, IL: Charles C Thomas.

\section{Author's Note:}

Address correspondence to: Li-ju Jang, Ph.D., assistant professor, School of Medical Sociology and Social Work, Chung Shan Medical University, No.100, Sec. 2, Dah-Ching Street, Taichung, 402, Taiwan , R.O.C. e-mail: ljang@csmu.edu.tw. 